\title{
Application of New Organocatalysts on Asymmetric Epoxidation of Chalcones
}

\author{
Anna Maria Deobald, * Arlene G. Corrêa, Márcio W. Paixão \\ Department of Chemistry, Federal University of São Carlos, São Carlos, 13565-905, SP, Brazil \\ *annamaria.de@gmail.com
}

Keywords: epoxidation, asymmetric, organocatalysis

\section{INTRODUCTION}

Optically active epoxy ketones are versatile building blocks for synthesis of several natural products and pharmaceuticals. In this context, the development of efficient methods for the asymmetric epoxidation of $\alpha, \beta$-enones is a interesting goal in organic synthesis. ${ }^{1}$ In order to achieve these purpose, the enantioselective organocatalysis is an useful tool in the synthesis of building blocks under practical conditions. In this work, we highlight the synthesis and application of a new class of organocatalysts in the enantioselective synthesis of epoxy ketones.

\section{RESULTS AND DISCUSSION}

The catalysts were easily prepared from $\mathrm{N}$-Bocproline in 2 steps (Scheme 1). Firstly the addition of Grignard reagent to $N$-Boc-proline ester, followed by deprotection of the Boc group with DMSO/MeOH and $\mathrm{KOH}$ gave the catalysts in good yields.

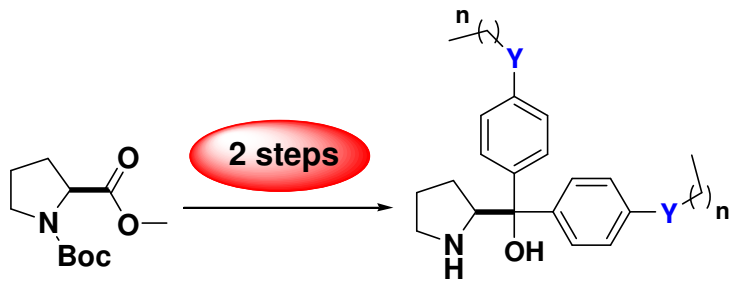

Scheme 1. Synthesis of organocatalysts 1a-d.

Having these catalysts, we started our studies with the chalcone, using $t-\mathrm{BuOOH}$ as oxidant reagent, 30 mol\% of catalyst and room temperature. The optimization of the reaction conditions are shown in Table 1.

After analyzing the reaction parameters such as solvent, time, temperature and the amount of the organocatalyst, we could observe that the best organocatalyst for this reaction is 1a (30 mol\%), wich gave the product in $88 \%$ yield and $82 \%$ ee, using hexane as a solvent. After recrystallization the ee was increased to $99 \%$ (Entry 2).
Table 1. Epoxidation of chalcones.



\begin{tabular}{ccccc}
\hline Entry & $\begin{array}{c}\text { Organo } \\
\text { catalyst }\end{array}$ & Solvent & $\begin{array}{c}\text { Yield } \\
(\%)^{\mathbf{a}}\end{array}$ & ee (\%) \\
\hline 1 & $\mathbf{1 a}$ & Hexane & 57 & $64^{\mathrm{c}}$ \\
2 & 1a & Hexane & 88 & $82\left(99^{\mathrm{d}}\right)$ \\
3 & $\mathbf{1 b}$ & Hexane & 66 & 50 \\
4 & $\mathbf{1 c}$ & Hexane & 55 & 50 \\
5 & $\mathbf{1 d}$ & Hexane & 45 & 50 \\
6 & $\mathbf{1 a}$ & H2O & 35 & 58 \\
7 & $\mathbf{1 a}$ & Ethanol & 16 & 34 \\
8 & $\mathbf{1 a}$ & THF & 15 & 50 \\
9 & $\mathbf{1 a}$ & Toluene & 32 & 50 \\
10 & $\mathbf{1 a}$ & PEG & 15 & 48 \\
11 & $\mathbf{1 a}$ & DMSO & 2 & 0 \\
12 & $\mathbf{1 a}$ & Hexane & 64 & $80\left(98^{\mathrm{d}}\right)^{\mathrm{e}}$ \\
13 & $\mathbf{1 a}$ & Hexane & 34 & $86\left(100^{\mathrm{d}}\right)^{\mathrm{f}}$ \\
14 & $\mathbf{1 a}$ & Hexane & 68 & $56\left(94^{\mathrm{d}}\right)^{\mathrm{g}}$ \\
15 & $\mathbf{1 a}$ & Hexane & 73 & $54^{\mathrm{h}}$ \\
\hline
\end{tabular}

${ }^{a}$ After chromatographic column. ${ }^{\circ}$ Determinated by HPLC using chiral column. ${ }^{c} 24 \mathrm{~h}$. ${ }^{\mathrm{d}}$ After recrystallization ${ }^{\mathrm{e}} 0^{\circ} \mathrm{C} C .{ }^{\mathrm{P}}-8{ }^{\circ} \mathrm{C} .{ }^{9}-8{ }^{\circ} \mathrm{C}$ $88 \mathrm{~h} .{ }^{\mathrm{h}} 20 \mathrm{~mol} \%$ of $\mathbf{1 a}$.

\section{CONCLUSION}

We have developed efficiently a new class of organocatalyst in the enatioselective synthesis of epoxiketones. Our efforts are now focused on the application of the optimized conditions to different $\alpha, \beta$-unsaturated ketones .

\section{ACKNOWLEDGEMENTS}

FAPESP (2009/07281-0 - 2010/07664-3), CNPq and CAPES.

\section{REFERENCES}

1 (a) Porter, M. J.; Skidmore, J. Chem. Commun. 2000, 1215. (b) Lauret, C. Tetrahedron: Asymmetry 2001, 12, 2359. 